\title{
A critical appraisal of the misoprostol removable, controlled-release vaginal delivery system of labor induction
}

\author{
Charlotte Patte' \\ Philippe Deruelle ${ }^{1,2}$ \\ 'Lille University Hospital, Jeanne \\ De Flandre Maternity, ${ }^{2}$ UPRES EA \\ 4489, Environnement périnatal \\ et santé, Faculté de médecine Henri \\ Warembourg, Université Lille 2, Lille, \\ France
}

This article was published in the following Dove Press journal:

International Journal of Women's Health

12 November 2015

Number of times this article has been viewed
Correspondence: Philippe Deruelle Pôle femme mère nouveau-né, Maternité Jeanne de Flandre, CHRU de Lille, I rue Eugène Avinée, 59037 Lille cedex, France Tel +33 320446307

Fax +33 32044631 I

Email philippe.deruelle@univ-lille2.fr
Background: Induction of labor is a major issue in pregnancy management. Finding strategies to increase rate and decrease time to vaginal delivery is an important goal, but maternal or neonatal safety must remain the primary objective. Misoprostol is a synthetic analogue of prostaglandin used off label to ripen the cervix and induce labor. The misoprostol vaginal insert (MVI) was designed to allow a controlled-release delivery of misoprostol (from 50 to $200 \mu \mathrm{g}$ ) with a removal tape. The objective of this review was to make a critical appraisal of this device referring to the literature.

Methods: A literature search was performed in the PubMed and Cochrane databases using the keywords "vaginal misoprostol insert".

Results: Several studies compared different doses of MVI $(50,100,150$, and $200 \mu \mathrm{g})$ with the $10 \mathrm{mg}$ dinoprostone insert. The $100 \mu \mathrm{g}$ MVI compared with the dinoprostone vaginal insert (DVI) showed similar efficacy and no significant differences in cesarean delivery rate. MVI $200 \mu \mathrm{g}$ compared with DVI showed a reduced time to vaginal delivery and oxytocin need but had an increased risk of uterine hyperstimulation. The rate of hyperstimulation syndrome was two to three times more frequent with the $200 \mu \mathrm{g}$ MVI than the $100 \mu \mathrm{g}$.

Conclusion: Current data suggest that the $100 \mu \mathrm{g}$ MVI would provide the best balance between efficacy and safety. Further studies should be performed to evaluate this dose, especially in high-risk situations needing induction of labor.

Keywords: prostaglandins, efficacy, safety, pregnancy

\section{Introduction}

Induction of labor is a very common obstetrical intervention and has been the subject of international recommendation from the World Health Organization (WHO) in $2011 .{ }^{1}$ The rate of induction of labor has doubled from the 1980s to the 1990s due to medical indication rise and achievement of cervical ripening techniques and stabilized, since then, approximately $20 \%$ of the patients in numerous developed countries $(23.3 \%$ in the USA in 2012 and $22.7 \%$ in France in 2010). ${ }^{2,3}$ It rises with gestational age, especially after 41 weeks of gestation, and with estimated fetal weight.

Because it is a very common obstetrical situation, physicians have to evaluate the better balance between efficacy of induction (ie, a high rate of vaginal delivery) and maternal and fetal safety of this intervention. Induction is indicated when the continuation of pregnancy endangers the well-being of the mother or the fetus. Induction of labor is proposed postterm or for pathological obstetrical situations such as gestational diabetes, gestational hypertension, preeclampsia, or fetal pathologies like intrauterine growth retardation or laparoschisis. 
Induction of labor can be obtained by two actions: cervical ripening or induction of contractions, which can be more or less combined. Cervical status has long been recognized as the most important prediction success factor of induction of labor, especially when cervical ripening is needed. ${ }^{4}$ The Bishop scoring system published in 1964 became the most widely used score to predict success induction of labor. ${ }^{5}$ The highest the score is, the better the proportion of vaginal delivery will be. A Bishop score of more than six allows obstetrician to induce labor with oxytocin by inducing contraction. In this situation, cervical ripening is useless. When the Bishop score is below 6, cervical ripening is needed. To ripen the cervix, nonpharmacologic or pharmacologic methods can be used. The WHO and the US Food and Drug Administration (FDA) recommend the use of prostaglandins as they have been shown to increase vaginal delivery rates within 24 hours of labor induction and decrease the need for the administration of oxytocin, with no effect on the rate of Cesarean delivery in women with an unscarred uterus. ${ }^{6}$

Prostaglandins are used for both cervical ripening and labor induction. There are two different types of prostaglandins: prostaglandins E2 (PGE2) that are well studied and broadly used and analogues of prostaglandins E1 (PGE1) called misoprostol. Misoprostol has only been approved for the prevention of gastric ulcers induced by nonsteroidal anti-inflammatory drugs. However, it is widely used in obstetrics as an adjunct to mifepristone in medical abortion, for treatment of postpartum hemorrhage in the presence of uterine atony, and also, for preinduction cervical ripening and stimulation of uterine contractions.

A Cochrane review of literature by Hofmeyr et al in 2010 compelled 121 studies that compared the use of vaginal misoprostol with other vaginal devices for the induction of labor. ${ }^{6}$ They found that time to vaginal delivery was lower with a dose of $25 \mu \mathrm{g}$ of misoprostol insert vaginally every 4 hours than conventional methods. The increased rate of uterine tachysystole with or without fetal heart rate (FHR) changes was not associated with an increased Cesarean rate. In contrast, there was no difference in serious neonatal or maternal mortality for women receiving misoprostol compared with women who received PGE2. The use of misoprostol have increased in many countries, especially in developing countries, as misoprostol can be stored at room temperature unlike other approved drugs that must be refrigerated.

However, the use of misoprostol is associated with some concerns, especially in countries where off-label use can lead to legal suits. The recommended dose of $25 \mu \mathrm{g}$ is not available widely. Thus, intravaginal administration of tablet fragments may not provide accurate dose strengths of misoprostol. Because of the uncertainty regarding the correct dose to use with tablets inserted vaginally and difficulty to remove those when adverse effects happen, a vaginal insert with removable tape and controlled-release reservoir of misoprostol has been developed. The misoprostol vaginal insert (MVI) is composed of misoprostol and nonbiodegradable hydrogel polymer that allows moisture absorption without dissolving. Misoprostol would be administered locally to the target tissues in a controlled-release manner. The vaginal application would provide a constant supply of misoprostol with low maximal systemic levels, thus expecting to reduce the incidence of adverse events. The vaginal insert's retrieval tape would allow easy, rapid removal of the product, immediately stopping delivery of additional drug if needed. The objective of this review was to make a critical appraisal of the misoprostol removable, controlledrelease vaginal delivery system for labor induction referring to the literature.

\section{Methods}

We performed a literature search, limited to English language, in the PubMed ${ }^{\circledR}$ and Cochrane library databases using the keywords "misoprostol vaginal insert". We considered pharmacological studies, retrospective studies, randomized clinical trials, secondary analyses, and review of use of the MVI. The Preferred Reporting Items for Systematic Reviews and Meta-analyses (PRISMA) guidelines were followed.

We mainly focused on the biodisponibility of misoprostol administered by MVI and also on efficacy and safety for maternal and fetal outcomes related to induction of labor. Even if randomized, clinical trials that compared misoprostol tablets introduced orally, sublingually, or vaginally with other cervical ripening methods were not included in our analysis but were used to discuss the current evidence available about the use of misoprostol as a labor induction drug. Indeed, because the aim of this review was to analyze the efficacy and safety of the MVI device, every other method using misoprostol for the induction of labor were excluded from the analysis of the results.

\section{Results Types of studies}

Thirty-six articles were found. Over the 36 items, 16 were directly related to MVI. We excluded eight trials about induction of labor using misoprostol tablets introduced vaginally compared with dinoprostone vaginal insert (DVI) and two 
using misoprostol tablets given orally compared with DVI. Five reviews or meta-analyses regarding DVI compared with misoprostol tablets or about DVI only for the induction of labor were also excluded. We also excluded one national survey on off-label use of misoprostol, one case report of complication after the use of oral misoprostol, and three papers about abortion using misoprostol.

\section{Description of the studies}

There were two pharmacological studies, ${ }^{7,8}$ one study about the maximum tolerable dose, ${ }^{9}$ four randomized doubleblind multicenter studies, ${ }^{10-12}$ six secondary analyses, two reviews, and one commentary of the last performed trial. The characteristics of the major studies are summarized in Table 1.

\section{Pharmacological studies}

Two Phase I trials about pharmacological characteristics of MVI were performed in both nonpregnant and pregnant women. Powers et al reported the pharmacokinetic parameters of misoprostol acid after introduction of MVI 100, 200, and $400 \mu \mathrm{g}$ compared with a $200 \mu \mathrm{g}$ misoprostol oral dose. ${ }^{7}$ This study included 12 nonpregnant women. Plasma concentration was dose proportional and peaked slower and for a longer lasting time with MVI compared with oral form. ${ }^{7}$ Rayburn et al in 2006 studied this device in 31 pregnant nulliparous women. They recorded the pharmacokinetics parameters after MVI dosing with 25, 50, 100, 200, and $300 \mu \mathrm{g}$. The results were similar to the Power's study with a dose-dependent plasma concentration and a quick elimination of the free acid of misoprostol in the systemic circulation after removal, with a half-life of less than an hour. ${ }^{8}$

\section{Comparison of different doses of misoprostol given by the MVI and comparisons of MVI vs DVI}

Several studies tried to compare different doses of misoprostol provided by MVI, and MVI to DVI. Castañeda et $\mathrm{al}^{9}$ in 2005 tried to evaluate the maximum tolerable dose of misoprostol delivered vaginally with a controlled-release insert. This was a multicenter Phase II trial involving nulliparous pregnant women experiencing induction of labor. Six patients for each dose were included. Five doses of MVI were used $(25,50,100,200$, and $300 \mu \mathrm{g})$. Median time to vaginal delivery was significantly shortened with doses from $100 \mu \mathrm{g}$ and above compared with $25 \mu \mathrm{g}$ reservoir. The $25 \mu \mathrm{g}$ group had a median time to vaginal birth of 43.3 hours compared with $14.2(P<0.01)$ for the $100 \mu \mathrm{g}$ group. Doses $>100 \mu \mathrm{g}$ did not reduce in a consistent manner the time to vaginal delivery, which suggests a threshold effect at this dose reservoir. Moreover, the proportion of vaginal birth within 24 hours in the $100 \mu \mathrm{g}$ group was significantly higher than in the $25 \mu$ g group ( $83 \%$ vs $0 \% ; P<0.003$ ). Regarding the safety of the compound, uterine hyperstimulation syndrome was defined by a uterine tachysystole (more than five contractions within 10 minutes) or uterine hypertonus (contraction lasting more than 2 minutes) associated with abnormal FHR. This syndrome was associated with a Cesarean delivery for two women in the $300 \mu \mathrm{g}$ group and none with the other groups. There were no low Apgar score and no adverse maternal event in this study.

After that trial, two Phase II studies were performed. Ewert et al in 2006, compared MVI 25, 50, 100, and $200 \mu \mathrm{g}$ for induction of labor in 124 pregnant women. ${ }^{10}$ The second one was the Wing trial published in 2011 that compared different doses of MVI at 100, 150, and $200 \mu \mathrm{g}$. ${ }^{11}$ The primary efficacy outcome of those studies was time to vaginal delivery for Ewert et $\mathrm{al}^{10}$ and proportion of vaginal birth within 24 hours for Wing. ${ }^{11}$

Wing et al published two Phase III trials with co-primary outcomes: time to vaginal delivery and Cesarean rate. ${ }^{12,13}$ Secondary end points included time to any delivery mode, time to onset of active labor, and oxytocin use.

The results of these different clinical trials are summarized in Tables 2-4 and will be discussed thereafter.

Six secondary analyses were realized using the results of these studies (Table 1). Pevzner et a $\left.\right|^{14,15}$ carried two secondary analysis of the Wing trial published in 2008 comparing MVI $50 \mu \mathrm{g}$ and $100 \mu \mathrm{g}$ to DVI. ${ }^{14,15}$ The first one, published in 2009 , analyzed the maternal and pregnancy characteristics that independently predict successful induction of labor. ${ }^{14}$ The major statistically significant results are compiled in Table 5. An age of $\geq 35$ and a BMI over $30 \mathrm{~kg} / \mathrm{m}^{2}$ at admission were independent factors of decrease in likelihood of vaginal birth (odds ratio $[\mathrm{OR}]=0.55,95 \%$ confidence interval $[\mathrm{CI}]=0.35-0.87$, and $\mathrm{OR}=0.63,95 \% \mathrm{CI}=0.43-0.91$, respectively). The Bishop score was not a predictor of successful induction of labor in this secondary analysis. The second one, published in 2011, tried to characterize the incidence and timing of cardiotocographic abnormalities associated with misoprostol and DVIs during labor induction. A total of $6.8 \%$ of MVI $50 \mu$ g-treated group experienced uterine tachysystole or hyperstimulation, compared with $17.4 \%$ with dinoprostone insert $(P<0.001)$ and $17.3 \%$ with MVI $100 \mu \mathrm{g}(P<0.001) .{ }^{15}$ There was no significant difference in incidence of FHR abnormalities that occurred with the study drug: $11.2 \%$ with dinoprostone 

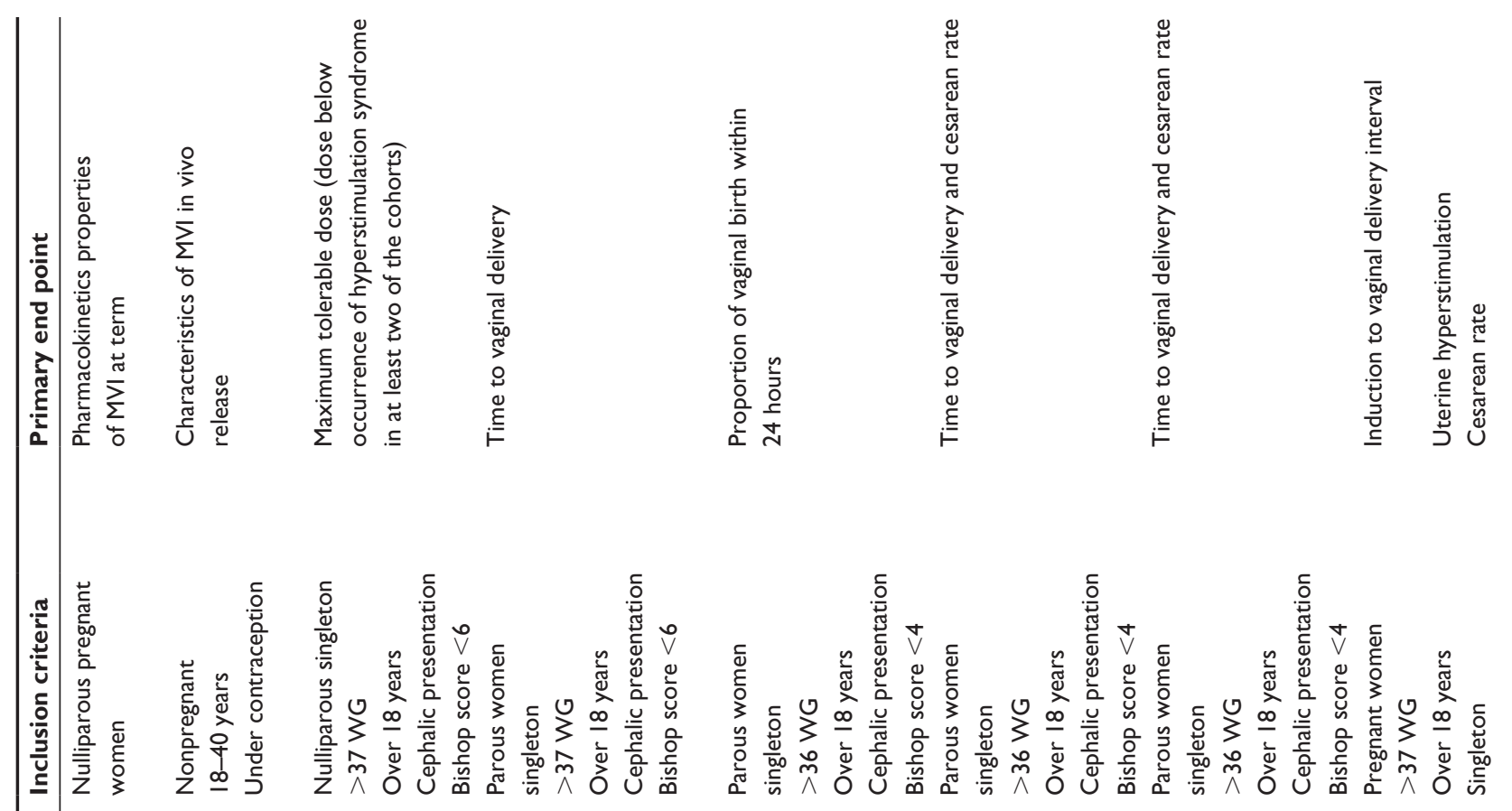

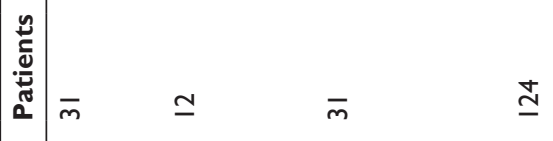

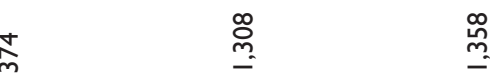

$\stackrel{\stackrel{\infty}{m}}{\stackrel{\infty}{m}}$

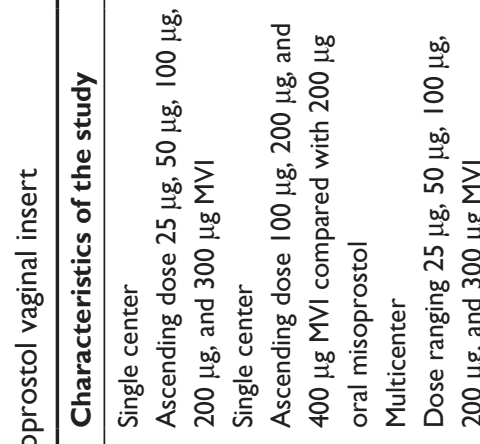

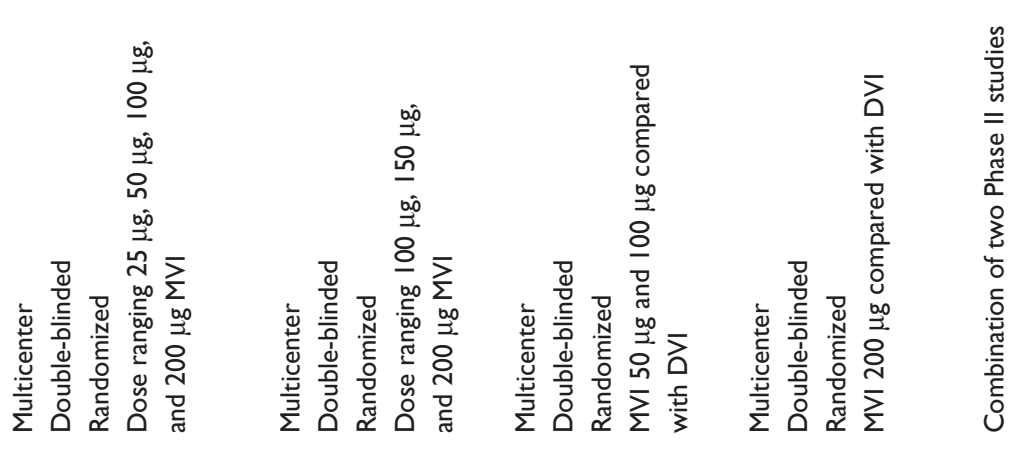

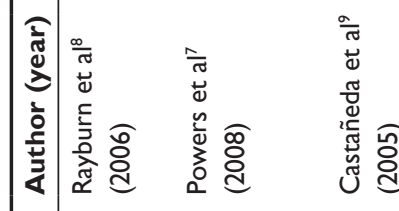
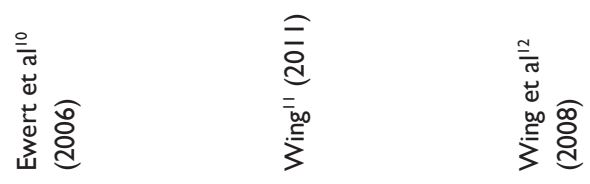

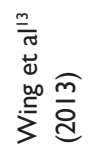
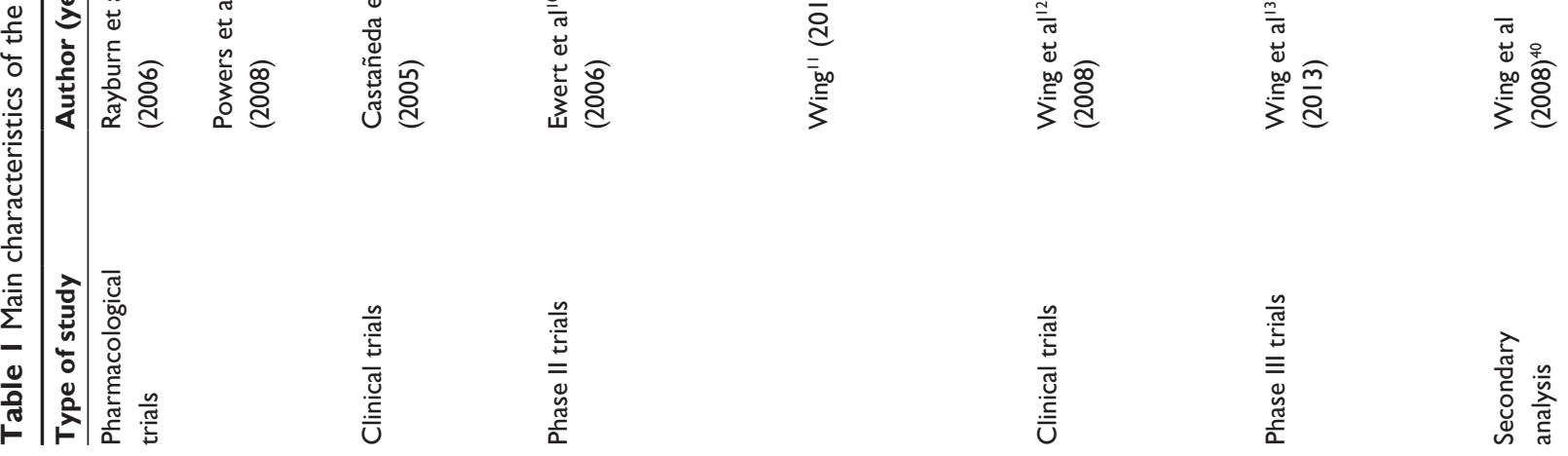

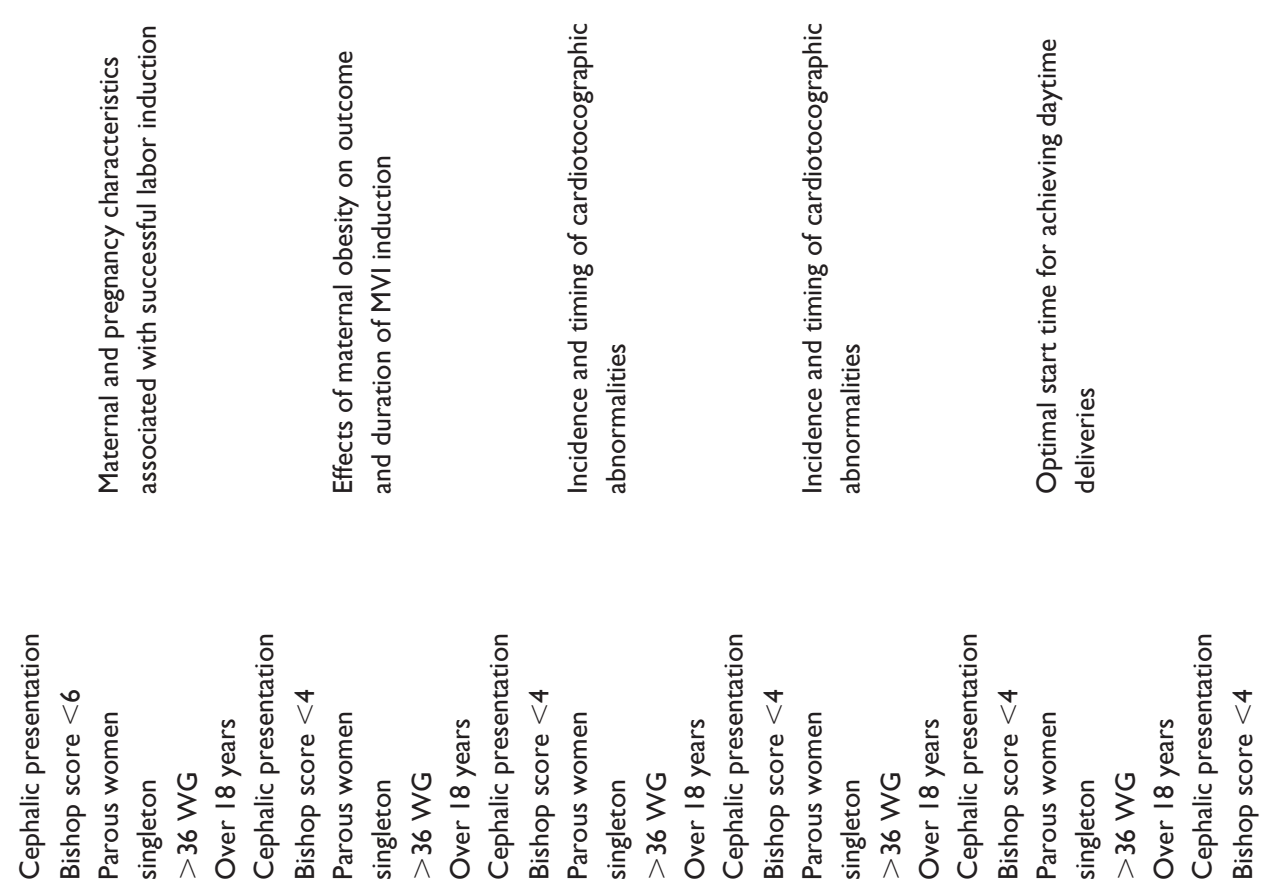

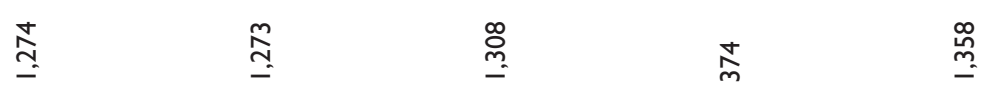
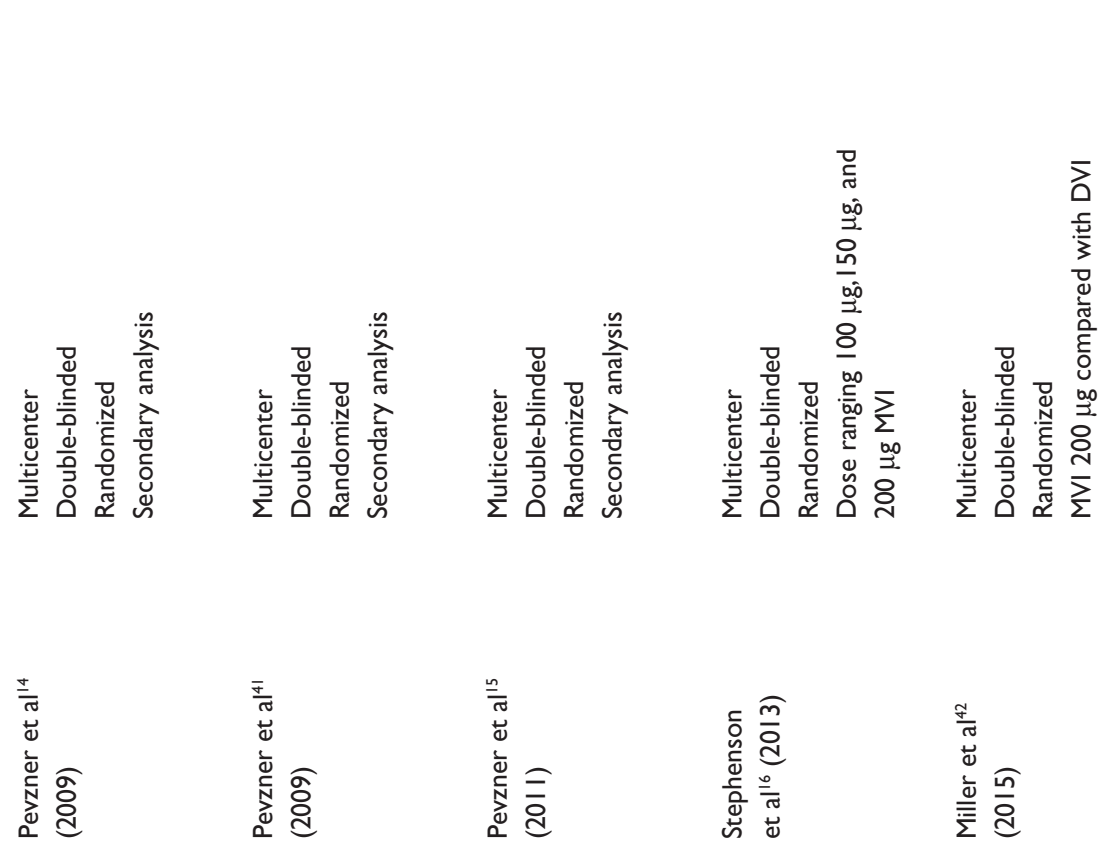
Table 2 Efficacy of misoprostol vaginal insert compared with dinoprostone vaginal insert and with different doses of misoprostol

\begin{tabular}{|c|c|c|c|c|}
\hline & Comparison & $\begin{array}{l}\text { Number } \\
\text { of patients }\end{array}$ & $\begin{array}{l}\text { Proportion of vaginal } \\
\text { birth (\%) within } 24 \text { hours }\end{array}$ & $\begin{array}{l}\text { Time to vaginal } \\
\text { birth (hour) }\end{array}$ \\
\hline \multirow[t]{5}{*}{ Ewert et al ${ }^{10}$} & Total & 124 & - & - \\
\hline & $25 \mu \mathrm{g}$ & 33 & 42 & - \\
\hline & $50 \mu \mathrm{g}$ & 29 & {$[79]$} & $19.1, P=0.76^{b}$ \\
\hline & $100 \mu g$ & 32 & $81 \quad P=0.003^{\mathrm{a}}$ & $13.1, P=0.003^{b}$ \\
\hline & $200 \mu \mathrm{g}$ & 30 & {$[70]$} & $10.6, P<\left.0.00\right|^{b}$ \\
\hline \multirow[t]{4}{*}{ Wing et al ${ }^{12}$} & Total & ।,297 & - & - \\
\hline & $50 \mu \mathrm{g}$ & 426 & & $35.4, P=0.0 I^{c}$ \\
\hline & $100 \mu \mathrm{g}$ & 440 & & $26.6, P=0.97^{c}$ \\
\hline & DVI & 431 & & 27.5 \\
\hline \multirow[t]{4}{*}{ Wing'l } & Total & 373 & - & - \\
\hline & $100 \mu \mathrm{g}$ & 117 & 63.8 & 23.3 \\
\hline & $150 \mu \mathrm{g}$ & 125 & 66.7 & $22.2, P=0.13^{d}$ \\
\hline & $200 \mu \mathrm{g}$ & $|3|$ & $76, P=0.057^{d}$ & $|7.4, P<0.00|^{d}$ \\
\hline
\end{tabular}

Notes: a Comparison for $P$ calculation is not specified; b ${ }^{\mathrm{C}}$ comparison between $25 \mu \mathrm{g}$ vs $50 \mu \mathrm{g}, 100 \mu \mathrm{g}$ and $200 \mu \mathrm{g} ;{ }^{\mathrm{c} v s} \mathrm{DVl}$; ${ }^{\mathrm{d} v s} \mathrm{I} 00 \mu \mathrm{g}$. - Not calculated.

Abbreviation: DVI, dinoprostone vaginal insert.

compared with $9.9 \%$ with MVI $50 \mu \mathrm{g}$ and $10.7 \%$ with MVI

$100 \mu \mathrm{g}$. Cardiotocographic abnormalities were less frequent with MVI $50 \mu \mathrm{g}$ than MVI $100 \mu \mathrm{g}$ or dinoprostone but clinical outcomes were the same among the groups.

Similarly, Stephenson et al tried to characterize the incidence and timing of FHR and cardiotocographic abnormalities associated with different doses of MVI. ${ }^{16}$ It was a secondary analysis of the Wing et al 2011 trial that studied MVI $100 \mu \mathrm{g}, 150 \mu \mathrm{g}$, and $200 \mu \mathrm{g}$. Although the rate of uterine tachysystole was significantly higher with $200 \mu \mathrm{g}$ dose compared with $100 \mu \mathrm{g}(P<0.001$, relative risk $[\mathrm{RR}]=2.11$, $95 \% \mathrm{CI}=1.39-3.22)$, uterine hyperstimulation syndrome was not significantly different between the two groups. Neonatal outcome were similar between the groups.

\section{Discussion}

\section{Pharmacology of misoprostol and focus on the MVI}

Misoprostol is a synthetic analogue of prostaglandin E1. It binds to prostaglandin receptors to induce biological effects in different tissues. Prostaglandins are secreted by the fetus and the placenta to sensitize the myometrium to oxytocin. The major effects of Prostaglandins analogues are effacement, softening, and dilatation of the cervix. They also increase myometrial contractility. Misoprostol is in vivo rapidly de-esterified to its free acid, which is an active metabolite. Plasma concentration of misoprostol is thus not possible to detect in the systemic circulation. It is the misoprostol acid metabolite that is instead measured.

Table 3 Safety of misoprostol vaginal insert compared with dinoprostone vaginal insert and different doses of misoprostol

\begin{tabular}{|c|c|c|c|c|c|}
\hline & Comparison & $\begin{array}{l}\text { Number } \\
\text { of patients }\end{array}$ & $\begin{array}{l}\text { Cesarean } \\
\text { rate }(\%)\end{array}$ & $\begin{array}{l}\text { UHS with } \\
\text { abnormal FHR (\%) }\end{array}$ & $\begin{array}{l}\text { Apgar score }<7 \\
\text { at } 5 \text { minutes }\end{array}$ \\
\hline \multirow[t]{5}{*}{ Ewert et a $\left.\right|^{10}$} & Total & 124 & & & \\
\hline & $25 \mu \mathrm{g}$ & 33 & 6 & 3 & 3 \\
\hline & $50 \mu \mathrm{g}$ & 29 & 3 & 0 & 0 \\
\hline & $100 \mu g$ & 32 & 0 & 6 & 0 \\
\hline & $200 \mu \mathrm{g}$ & 30 & 10 & 10 & 0 \\
\hline \multirow[t]{4}{*}{ Wing et al ${ }^{12}$} & Total & I,297 & & & \\
\hline & $50 \mu \mathrm{g}$ & 426 & $28, P=0.59^{a}$ & 2.9, $P=0.03^{a}$ & I.6, $P=0.55^{\mathrm{a}}$ \\
\hline & $100 \mu \mathrm{g}$ & 440 & $27.8, P=0.64^{a}$ & 6. I, $P=0.89^{a}$ & $0.9, P=I^{a}$ \\
\hline & DVI & 431 & 26.4 & 6.4 & 0.9 \\
\hline \multirow[t]{4}{*}{ Wing"l } & Total & 373 & & & \\
\hline & $100 \mu \mathrm{g}$ & 117 & 31.4 & 6.8 & 0 \\
\hline & $150 \mu \mathrm{g}$ & 125 & $30.4, P=0.89^{b}$ & $9.6, P=0.49^{b}$ & 0.8 \\
\hline & $200 \mu \mathrm{g}$ & $13 \mid$ & $22.9, P=0.15^{b}$ & $12.2, P=0.2^{b}$ & 0.8 \\
\hline
\end{tabular}

Notes: a vs DVI; ${ }^{b}$ vs $100 \mu g$.

Abbreviations: DVI, dinoprostone vaginal insert; UHS, uterine hyperstimulation syndrome; FHR, fetal heart rate. 
Table 4 Focus on the results of the study comparing misoprostol vaginal insert $200 \mu g$ and dinoprostone vaginal insert

\begin{tabular}{|c|c|c|c|}
\hline $\mathrm{n}=\mathrm{I}, 358$ patients & MVI $200 \mu \mathrm{g}$ & DVI & \\
\hline Number of patients & 678 & 680 & \\
\hline Proportion of vaginal birth within 24 hours (\%) & 54.6 & 34.0 & $P<0.001$ \\
\hline Time to vaginal birth (hour) & 21.5 & 32.8 & $P<0.00$ I \\
\hline Cesarean rate $(\%)$ & 26 & 27.1 & NS \\
\hline \multirow[t]{3}{*}{ UHS with abnormal FHR (\%) } & 10.3 & 2.6 & $P<0.05$ \\
\hline & & & $\mathrm{RR}=3.9$ \\
\hline & & & $95 \% \mathrm{Cl}=2.35-6.48$ \\
\hline \multirow[t]{3}{*}{ Apgar score $<7$ at 5 minutes } & 2.1 & 1.0 & NS \\
\hline & & & $\mathrm{RR}=2$ \\
\hline & & & $95 \% \mathrm{Cl}=0.8 \mathrm{I}-4.94$ \\
\hline \multirow[t]{3}{*}{ Neonatal encephalopathy } & 0.6 & 0.1 & NS \\
\hline & & & $\mathrm{RR}=4$ \\
\hline & & & $95 \% \mathrm{Cl}=0.45-35.80$ \\
\hline
\end{tabular}

Note: Data from Wing et al. ${ }^{12}$

Abbreviations: MVI, misoprostol vaginal insert; DVI, dinoprostone vaginal insert; NS, not statistically different; UHS, uterine hyperstimulation syndrome; FHR, fetal heart rate; $\mathrm{RR}$, relative risk; $\mathrm{Cl}$, confidence interval.

Misoprostol administration can be oral, sublingual, or vaginal. The oral administration provides a slow plasmatic concentration and a low bioavailability. The sublingual administration provides a high plasmatic concentration and bioavailability. The vaginal administration allows a good bioavailability and a low plasmatic level, but detectable plasma concentration last longer after vaginal administration. Tang et al have compared pharmacokinetic parameters of four different routes of administration of a single dose of $400 \mu \mathrm{g}$ of misoprostol. ${ }^{17}$ They found that sublingual and oral administrations have the quickest onset of action when compared with vaginal administration with or without water. Sublingual administration can achieve the highest plasma concentration when compared with all other routes of administration. The systemic bioavailability was also highest after sublingual administration of misoprostol. Oral administration had only half of the bioavailability of sublingual administration. Different studies comparing the pharmacokinetics profiles of vaginal and oral administration of misoprostol found similar results. ${ }^{17-19}$ The peak plasma concentration of misoprostol free acid was higher and achieved earlier after oral administration, but the detectable plasma concentration lasted longer after vaginal administration. In contrast, the systemic bioavailability of vaginally administered misoprostol was not

Table 5 Major results of the study of Pevzner et al

\begin{tabular}{lll}
\hline Characteristics & $\begin{array}{l}\text { Vaginal } \\
\text { delivery (\%) }\end{array}$ & $\begin{array}{l}\text { Adjusted } \\
\text { OR (95\% CI) }\end{array}$ \\
\hline Multiparous women & 88.25 & $5.2(3.7-7.4 I)$ \\
Elective induction of labor $(16.5 \%)$ & 86.7 & $2.1(1.13-3.8)$ \\
Height I65 cm or more & 76 & $2.0(1.47-2.72)$ \\
\hline
\end{tabular}

Note: Data from Pevzner et al. ${ }^{14}$

Abbreviations: $\mathrm{OR}$, odds ratio; $\mathrm{Cl}$, confidence interval. consistent between the studies. Zieman et al found that the bioavailability of vaginally administered misoprostol was three times higher than the oral form, whereas Tang et al had similar results between the two regimens. Those differences may be explained by a wide variation in absorption of vaginal misoprostol. Moreover, despite similar bioavailability, use of misoprostol was first studied for the induction of abortion or second-trimester ending of pregnancies. Regarding those studies, more favorable clinical effects have been demonstrated with vaginal administration when compared with oral administration. ${ }^{20,21}$ Thus, taken together, those data suggest that misoprostol introduced vaginally seems to be the most appropriate way to induce contractions. One can then extrapolate that vaginal route for induction of labor with misoprostol could be the best option for high rate of vaginal deliveries. As induction of labor can occur in situations where the vaginal environment can be modified, Castañeda et al tested the MVI device in different pathological conditions. ${ }^{9}$ They showed that a vaginal $\mathrm{pH}$ change due to vaginal secretions, ruptured membranes, or blood does not affect the release of misoprostol in vivo or in vitro.

Powers et al studied the pharmacokinetic profile of the MVI with different doses on nonpregnant women and showed in their study that after oral administration of $200 \mu \mathrm{g}$ of misoprostol, plasma concentration of misoprostol acid peaked quickly in approximately 20 minutes. ${ }^{7}$ With the MVI, misoprostol acid concentration in plasma was constant and durable during the first 12 hours of introduction and then decreased gradually. The maximum plasma concentration was less important and occurred a lot later for the MVI than the oral form. However, systemic exposure to misoprostol was three times greater with the $200 \mu \mathrm{g}$ MVI than 
the $200 \mu \mathrm{g}$ oral tablet. Moreover, plasma concentration was dose proportional. Rayburn et $\mathrm{al}^{8}$ had the same conclusions using this device on pregnant women. Misoprostol was mainly excreted renally with a half-life less than an hour after removal of the vaginal insert. Those two Phase I trials allow to think that misoprostol introduced vaginally and with a controlled-release insert has a greater biodisponibility with a lower plasma concentration than oral tablets. Thus, as adverse events due to misoprostol, such as hyperstimulation syndrome, are related to high plasma concentration, MVI could minimize those adverse events because of its pharmacokinetics parameters.

\section{What are the current evidences of the use of misoprostol for induction of labor?}

Misoprostol as an induction agent has been extensively studied. Hofmyer et $\mathrm{al}^{6}$ have compiled results of those studies in a large meta-analysis. They showed that misoprostol is an effective induction agent. Indeed, compared with placebo, misoprostol was associated with reduced failure to achieve vaginal delivery within 24 hours $(R R=0.51,95 \%$ $\mathrm{CI}=0.37-0.71)$. The need for oxytocin was reduced with misoprostol in comparisons with other conventional methods of induction of labor such as prostaglandins.

Regarding the safety of this molecule, several studies have shown an increased rate of side effects such as uterine tachysystole. Uterine tachysystole due to misoprostol was first reported by Mariani Neto et al in 1987 unrelated to dosage. ${ }^{22}$ Sanchez-Ramos et al in 1995 published data that confirmed an increased incidence of uterine tachysystole that was not associated with a statistically significant increase in adverse fetal outcome. ${ }^{23}$ Hofmyer confirmed these data as they found that uterine hyperstimulation without FHR changes was increased with misoprostol compared with prostaglandins but lower doses of misoprostol compared with higher doses were associated with less uterine hyperstimulation, with and without FHR changes. Thus, the current dose of misoprostol recommended by WHO for induction of labor is $25 \mu \mathrm{g}$ every $3-6$ hours.

Uterine rupture following the use of misoprostol in patients with a history of Cesarean section is probably the most important issue of using this drug. Uterine rupture following the use of misoprostol for the induction of labor in patients with previous cesarean section has been reported by several studies. ${ }^{24-28}$ However, these studies were of low quality. Some randomized studies (three over 35) that compared misoprostol to other induction of labor methods included some patients with scarred uterus, but it was not sufficient to assess this criterion. ${ }^{26,29-32}$ In a study comparing PGE2 and PGE1, Blanchette et al reported a uterine rupture rate of $18.8 \%$ (three cases) in the subgroup of 16 patients with a previous cesarean section. ${ }^{26}$ A trial was interrupted early because of the rate of uterine rupture in the misoprostol group (2/17) after introduction of two and three doses of $25 \mu \mathrm{g}$ misoprostol every 6 hours. ${ }^{33}$ Aslan et al reported a rupture rate of $9.7 \%$ with misoprostol in 41 patients induced with a history of a previous Cesarean section. The protocol required a dose of $50 \mu \mathrm{g}$ introduced vaginally followed by a second dose 4 hours later, and then $100 \mu \mathrm{g}$ every 4 hours with a maximum of six doses. ${ }^{34}$ With lower doses $(25 \mu \mathrm{g}$ introduced vaginally repeated 3 hours later), in a retrospective analysis of 89 patients by Plaut et al a rupture rate of $5.6 \%$ was observed. ${ }^{35}$

\section{Efficacy of MVI}

Several studies aimed to compare different doses of MVI and MVI with DVI. Those studies were well designed and mainly conceived to answer to the question of efficacy. All inclusion criteria were similar between the studies. Patients with previous Cesarean or more than four vaginal births were excluded.

Obviously, misoprostol has a dose-dependent effect (Table 2). The efficacy, evaluated by the time to vaginal delivery and the rate of vaginal delivery, increased with the doses from 25 to $100 \mu \mathrm{g}$ but was almost similar with doses above $100 \mu \mathrm{g}$, that is, between 100 and $200 \mu \mathrm{g} .{ }^{9}$ In 2005, Castañeda et al studied the maximum tolerable dose of MVI on pregnant women and efficacy of different MVI doses. They showed that when $>100 \mu \mathrm{g}$ of misoprostol was administered, the median time to vaginal delivery was not shortened. These results were confirmed by Ewert et al in 2006 who compared different doses of MVI with an efficacy end point of reduced time to vaginal delivery. ${ }^{10}$ Time was significantly reduced with 100 and $200 \mu \mathrm{g}$ MVI compared with lower doses. A few years later, Wing found that the time to vaginal delivery was significantly reduced with the administration of MVI $200 \mu \mathrm{g}$, but the proportion of women who delivered vaginally by 24 hours was not statistically different (NS) for $200 \mu \mathrm{g}$ compared with $100 \mu \mathrm{g} .{ }^{11}$

When compared with DVI, the $100 \mu \mathrm{g}$ MVI had a similar efficacy for time to vaginal delivery (1,596 with MVI $100 \mu \mathrm{g}$ vs 1,650 with DVI, NS) and for Cesarean deliveries (28.3\% with MVI $100 \mu \mathrm{g}$ vs $27.1 \%$ with DVI, NS). ${ }^{12}$ When MVI $200 \mu \mathrm{g}$ was compared with DVI, time to vaginal delivery in MVI group was reduced (Table 4, 21.5 hours in the MVI 
group vs 32.8 hours in the DVI group, $P<0.001)$. The proportion of vaginal birth was NS between $200 \mu \mathrm{g}$ MVI and DVI $(73.3 \%$ vs $71.6 \%, P=0.50){ }^{13}$

If we consider the patients' point of view, time to delivery is an important judgment criterion. When we ask the patients regarding the best care they would prefer, they claim for a quick and efficient labor without pain. ${ }^{36}$ Shetty et al interviewed patients about their experience of induced labor. Postinduction, $40 \%$ of the women indicated that the speed of the induction was the most important aspect they would like to change about their induction if they were to have another one. ${ }^{37}$

Thus, regarding efficacy and patients' expectations, $200 \mu \mathrm{g}$ would be the right dose for MVI as the time to delivery is reduced with similar rate of vaginal delivery compared with the $100 \mu \mathrm{g}$ MVI or the current available DVI. However, a work that studies this specific question should be carried out to answer this hypothesis.

\section{Safety of MVI}

Maternal and neonatal safety is critical when we consider the outcome of labor induction. Adverse events related to safety of MVI include emergency $\mathrm{C}$-section, postpartum hemorrhage, uterine tachysystole with and without FHR abnormalities, meconium-stained amniotic fluid, Apgar score below 7, fetal acidosis, or neonatal complications. In all the studies but one, ${ }^{16}$ these outcomes were considered as secondary judgment criteria, which means that the number of patients was not calculated based on them. Then, we can assume that the number of patients in the different publications might be too small to show a difference as some adverse events related to labor induction, especially severe events such as fetal acidosis, are infrequent.

The most problematic issue concerns the occurrence of uterine tachysystole associated with FHR pattern or hyperstimulation syndrome (Table 3 ). The rate of uterine hyperstimulation syndrome was found to be $10 \%$ in the study by Ewert et $\mathrm{al}^{10} 10.3 \%$ by Wing et $\mathrm{al}^{13}$ and $12.2 \%$ by Wing $^{11}$ with $200 \mu \mathrm{g}$ MVI. This rate was two to three times higher than the rate observed with the $100 \mu \mathrm{g}$ MVI $(3 \%$ in the study by Ewert et $\mathrm{al}^{10} 6.1 \%$ by Wing et $\mathrm{al}^{12}$ and $6.8 \%$ by Wing $\left.^{11}\right)$ or with DVI ( $6.4 \%$ by Wing et $\mathrm{al}^{12}$ and $2.6 \%$ by Wing et $\mathrm{al}^{13}$ ). It is well known that the reduced time to vaginal delivery with vaginal misoprostol is counterbalanced by an increase in uterine hyperstimulation with or without FHR abnormalities. All the trials using the MVI demonstrated a dose-dependent increase in uterine hyperstimulation syndrome. The highest rates were found with the $200 \mu \mathrm{g}$ dose.
Nonreassuring FHR was not systematically associated with uterine hyperstimulation.

The first studies (Ewert et al, ${ }^{10}$ Wing et al, ${ }^{12}$ and Wing ${ }^{11}$ ) described a dose-dependent effect for uterine hyperstimulation syndrome but did not find an impact on the rates of C-section or Apgar score below 7 and fetal acidosis. Similar results between DVI and MVI $100 \mu \mathrm{g}$ for hyperstimulation syndrome and low Apgar scores were obtained in the 2008 Wing's trial. The most recent study in 2013 highlighted a significant difference between DVI and MVI $200 \mu \mathrm{g}$ for hyperstimulation syndrome with a RR of 3.9 (95\% CI $=2.35-6.48, P<0.05)$. The risk of low Apgar score was doubled and the risk of neonatal encephalopathy multiplied by 4 with MVI compared with DVI but the difference was not significant. Those results have to be taken cautiously because those trials were not powered to demonstrate a difference for these criteria. Using a two-sided $\chi^{2}$ test with an alpha risk of $5 \%$ and a power of $80 \%$, the necessary number of patients to detect a difference would have been 6,206 patients for Apgar score $<7$ at 5 minutes, 5,860 patients for encephalopathy, or 10,410 patients for fetal acidosis.

The Cesarean rate was not increased in any studies using MVI. ${ }^{9-13}$ Cesarean attributable to nonreassuring FHR occurred more often with MVI $200 \mu \mathrm{g}$ compared with MVI $100 \mu \mathrm{g}$, but the difference was not statistically significant. ${ }^{12}$ For Wing in 2013, not only was this rate not significantly different, but it did not show noninferiority of MVI compared with DVI. The most common reason for Cesarean delivery was adverse event in both groups. It concerns hyperstimulation syndrome for MVI $200 \mu \mathrm{g}$ group and arrest of cervical dilatation for DVI group. ${ }^{13}$ This study included only a lowrisk population at/or near term. Many situations that require labor induction include high-risk fetuses such as intrauterine growth retardation, placental insufficiency (gestational hypertension and preeclampsia), and gestational diabetes. In these cases, we cannot rule out that the increased rate of tachysystole may not lead to more frequent Cesarean section or neonatal acidosis.

For maternal and neonatal safety, evidence suggests that the MVI $100 \mu \mathrm{g}$ is better than the $200 \mu \mathrm{g}$. The rate of per partum and neonatal complications are significantly lower with the $100 \mu \mathrm{g}$ MVI and similar to DVI.

Past studies about the use of misoprostol introduced vaginally lead to recommend low-dose misoprostol, $25 \mu \mathrm{g}$ given every 6 hours. For a period of 24 hours, this represents a total dose of $100 \mu \mathrm{g}$. This is very similar to the total dose of $100 \mu \mathrm{g}$ released by MVI. It is important to consider this 
extrapolation with caution, as the tablets have not been designed for the vaginal route. Comparative research is needed to conclude that the total given doses is identical for tablets and MVI.

In conclusion, the $200 \mu \mathrm{g}$ MVI allows a faster delivery but increases the risk of hyperstimulation syndrome, whereas the $100 \mu \mathrm{g}$ MVI has the same rate of vaginal delivery with a mean time from induction to delivery prolonged by 3 hours. With $100 \mu \mathrm{g}$, there is far less uterine tachysystole associated with FHR patterns compared with the $200 \mu \mathrm{g}$ MVI. It is true that many patients complain about the duration of induction. In a study about women's perceptions, expectations, and satisfaction with induced labor, all patients were induced with vaginal prostaglandins. Even if $40 \%$ of the patients felt their induction took longer than expected, $73.5 \%$ were generally satisfied with the induction process. When we consider their expectations before induction, they hope for a fast but safe induction. A total of $44.6 \%$ of women fear more chance of babies to be distressed and $70.7 \%$ want the induction method to be safe for the baby and them even if it takes longer. ${ }^{37}$ After induction of labor, some patients blame the medical team for a stressful birth experience, especially when they had an emergency C-section due to FHR patterns. These emergency Cesarean sections are most of the time experienced as a mental trauma and lead to posttraumatic stress disorders during the postpartum period. ${ }^{38}$ It is thereby necessary to find the best balance between efficacy and safety to answer both doctors' and patients' expectations. The current data suggest that the $100 \mu \mathrm{g}$ MVI provides the best compromise for these outcomes. Regarding those considerations, it is therefore surprising that the choice of the pharmacological industry was to introduce the $200 \mu \mathrm{g}$ dosage to the market.

It is clear that introducing on the market a labeled product will address a number of legal problems. However, as suggested by Rouse in an editorial, despite the methodological rigor of Wing trial, ${ }^{13}$ the use of $200 \mu \mathrm{g}$ is not justified because even if it shortened the time to vaginal delivery, it increases uterine tachysystole, fetal distress, and use of tocolysis. He then thinks that one would replace an inexpensive and effective generic alternative with a much more expensive proprietary product that is probably not any better. ${ }^{39}$ Further studies should be performed to compare the $100 \mu \mathrm{g}$ MVI and low misoprostol dose (25 $\mu$ g every 6 hours) using tablets given orally or vaginally.

\section{Disclosure}

The authors report no conflicts of interest in this work.

\section{References}

1. Organization WH. WHO Recommendations for Induction of Labour. Geneva: World Health Organization; 2011. Available from: http://apps. who.int//iris/handle/10665/44531. Accessed May 30, 2015.

2. Products-Data Briefs-Number $155 ; 2014$. Available from: http://www. cdc.gov/nchs/data/databriefs/db155.htm. Accessed May 30, 2015.

3. Blondel B, Lelong N, Kermarrec M, Goffinet F; Coordination nationale des Enquêtes Nationales Périnatales. La santé périnatale en France métropolitaine de 1995 à 2010: résultats des enquêtes nationales périnatales [Trends in perinatal health in France between 1995 and 2010: results from the National Perinatal Surveys]. J Gynécologie Obstétrique Biol Reprod. 2012;41(2):151-166. French.

4. Baacke KA, Edwards RK. Preinduction cervical assessment. Clin Obstet Gynecol. 2006;49(3):564-572.

5. Bishop EH. Pelvic scoring for elective induction. Obstet Gynecol. 1964; 24:266-268.

6. Hofmeyr GJ, Gülmezoglu AM, Pileggi C. Vaginal misoprostol for cervical ripening and induction of labour. Cochrane Database Syst Rev. 2010;(10):CD000941.

7. Powers BL, Wing DA, Carr D, Ewert K, Di Spirito M. Pharmacokinetic profiles of controlled-release hydrogel polymer vaginal inserts containing misoprostol. J Clin Pharmacol. 2008;48(1):26-34.

8. Rayburn WF, Powers BL, Plasse TF, Carr D, Di Spirito M. Pharmacokinetics of a controlled-release misoprostol vaginal insert at term. J Soc Gynecol Investig. 2006;13(2):112-117.

9. Castañeda CS, Izquierdo Puente JC, Leon Ochoa RA, Plasse TF, Powers BL, Rayburn WF. Misoprostol dose selection in a controlledrelease vaginal insert for induction of labor in nulliparous women. Am J Obstet Gynecol. 2005;193(3 pt 2):1071-1075.

10. Ewert K, Powers B, Robertson S, Alfirevic Z. Controlled-release misoprostol vaginal insert in parous women for labor induction: a randomized controlled trial. Obstet Gynecol. 2006;108(5):1130-1137.

11. Wing DA; Misoprostol Vaginal Insert Consortium. Misoprostol vaginal insert compared with dinoprostone vaginal insert: a randomized controlled trial. Obstet Gynecol. 2008;112(4):801-812.

12. Wing DA, Brown R, Plante LA, Miller H, Rugarn O, Powers BL. Misoprostol vaginal insert and time to vaginal delivery: a randomized controlled trial. Obstet Gynecol. 2013;122(2 pt 1):201-209.

13. Wing DA, Miller H, Parker L, Powers BL, Rayburn WF; Misoprostol Vaginal Insert Miso-Obs-204 Investigators. Misoprostol vaginal insert for successful labor induction: a randomized controlled trial. Obstet Gynecol. 2011;117(3):533-541.

14. Pevzner L, Rayburn WF, Rumney P, Wing DA. Factors predicting successful labor induction with dinoprostone and misoprostol vaginal inserts. Obstet Gynecol. 2009;114(2 pt 1):261-267.

15. Pevzner L, Alfirevic Z, Powers BL, Wing DA. Cardiotocographic abnormalities associated with misoprostol and dinoprostone cervical ripening and labor induction. Eur J Obstet Gynecol Reprod Biol. 2011; 156(2):144-148.

16. Stephenson ML, Powers BL, Wing DA. Fetal heart rate and cardiotocographic abnormalities with varying dose misoprostol vaginal inserts. J Matern Fetal Neonatal Med. 2013;26(2):127-131.

17. Tang OS, Schweer H, Seyberth HW, Lee SWH, Ho PC. Pharmacokinetics of different routes of administration of misoprostol. Hum Reprod. 2002;17(2):332-336.

18. Zieman M, Fong SK, Benowitz NL, Banskter D, Darney PD. Absorption kinetics of misoprostol with oral or vaginal administration. Obstet Gynecol. 1997;90(1):88-92.

19. Tang OS, Gemzell-Danielsson K, Ho PC. Misoprostol: pharmacokinetic profiles, effects on the uterus and side-effects. Int J Gynaecol Obstet. 2007;99(suppl 2):S160-S167.

20. el-Refaey H, Rajasekar D, Abdalla M, Calder L, Templeton A. Induction of abortion with mifepristone (RU 486) and oral or vaginal misoprostol. N Engl J Med. 1995;332(15):983-987.

21. Ho PC, Ngai SW, Liu KL, Wong GC, Lee SW. Vaginal misoprostol compared with oral misoprostol in termination of second-trimester pregnancy. Obstet Gynecol. 1997;90(5):735-738. 
22. Mariani Neto C, Leão EJ, Barreto EM, Kenj G, De Aquino MM, Tuffi VH. Uso do misoprostol para indução do parto com feto morto [Use of misoprostol for labor induction in stillbirth]. Rev Paul Med. 1987;105(6):325-328. Portuguese.

23. Sanchez-Ramos L, Peterson DE, Delke I, Gaudier FL, Kaunitz AM. Labor induction with prostaglandin E1 misoprostol compared with dinoprostone vaginal insert: a randomized trial. Obstet Gynecol. 1998;91(3): 401-405.

24. Bennett BB. Uterine rupture during induction of labor at term with intravaginal misoprostol. Obstet Gynecol. 1997;89(5 pt 2):832-833.

25. Sciscione AC, Nguyen L, Manley JS, Shlossman PA, Colmorgen GH. Uterine rupture during preinduction cervical ripening with misoprostol in a patient with a previous caesarean delivery. Aust $N Z J$ Obstet Gynaecol. 1998;38(1):96-97.

26. Blanchette HA, Nayak S, Erasmus S. Comparison of the safety and efficacy of intravaginal misoprostol (prostaglandin E1) with those of dinoprostone (prostaglandin E2) for cervical ripening and induction of labor in a community hospital. Am J Obstet Gynecol. 1999;180(6 pt 1): 1551-1559.

27. Mathews JE, Mathai M, George A. Uterine rupture in a multiparous woman during labor induction with oral misoprostol. Int J Gynaecol Obstet. 2000;68(1):43-44.

28. Khosla AH, Sirohiwal D, Sangwan K. A still birth and uterine rupture during induction of labour with oral misoprostol. Aust $N$ Z J Obstet Gynaecol. 2002;42(4):414-414.

29. Carlan SJ, Bouldin S, O’Brien WF. Extemporaneous preparation of misoprostol gel for cervical ripening: a randomized trial. Obstet Gynecol. 1997;90(6):911-915.

30. Chuck FJ, Huffaker BJ. Labor induction with intravaginal misoprostol versus intracervical prostaglandin E2 gel (Prepidil gel): randomized comparison. Am J Obstet Gynecol. 1995;173(4):1137-1142.

31. Perry KG, Larmon JE, May WL, Robinette LG, Martin RW. Cervical ripening: a randomized comparison between intravaginal misoprostol and an intracervical balloon catheter combined with intravaginal dinoprostone. Am J Obstet Gynecol. 1998;178(6):1333-1340.
32. Vengalil SR, Guinn DA, Olabi NF, Burd LI, Owen J. A randomized trial of misoprostol and extra-amniotic saline infusion for cervical ripening and labor induction. Obstet Gynecol. 1998;91(5 pt 1):774-779.

33. Wing DA, Lovett K, Paul RH. Disruption of prior uterine incision following misoprostol for labor induction in women with previous cesarean delivery. Obstet Gynecol. 1998;91(5 pt 2):828-830.

34. Aslan H, Unlu E, Agar M, Ceylan Y. Uterine rupture associated with misoprostol labor induction in women with previous cesarean delivery. Eur J Obstet Gynecol Reprod Biol. 2004;113(1):45-48.

35. Plaut MM, Schwartz ML, Lubarsky SL. Uterine rupture associated with the use of misoprostol in the gravid patient with a previous cesarean section. Am J Obstet Gynecol. 1999;180(6 pt 1):1535-1542.

36. Impey L. Maternal attitudes to amniotomy and labor duration: a survey in early pregnancy. Birth. 1999;26(4):211-214.

37. Shetty A, Burt R, Rice P, Templeton A. Women's perceptions, expectations and satisfaction with induced labour - a questionnaire-based study. Eur J Obstet Gynecol Reprod Biol. 2005;123(1):56-61.

38. Ryding EL, Wijma B, Wijma K. Posttraumatic stress reactions after emergency cesarean section. Acta Obstet Gynecol Scand. 1997;76(9): $856-861$.

39. Rouse DJ. The misoprostol vaginal insert: déjà vu all over again. Obstet Gynecol. 2013;122(2 pt 1):193-194.

40. Wing DA, Powers BL, Rayburn WF. Determining dose and endpoints of a controlled-release misoprostol vaginal insert for a phase III trial. J Reprod Med. 2008;53(9):695-696.

41. Pevzner L, Powers BL, Rayburn WF, Rumney P, Wing DA. Effects of maternal obesity on duration and outcomes of prostaglandin cervical ripening and labor induction. Obstet Gynecol. 2009;114(6):1315-1321.

42. Miller H, Goetzl L, Wing DA, Powers B, Rugarn O. Optimising daytime deliveries when inducing labour using prostaglandin vaginal inserts. J Matern Fetal Neonatal Med. 2015;19:1-6.
International Journal of Women's Health

\section{Publish your work in this journal}

The International Journal of Women's Health is an international, peerreviewed open-access journal publishing original research, reports, editorials, reviews and commentaries on all aspects of women's healthcare including gynecology, obstetrics, and breast cancer. The manuscript management system is completely online and includes

\section{Dovepress}

a very quick and fair peer-review system, which is all easy to use. Visit http://www.dovepress.com/testimonials.php to read real quotes from published authors. 